\title{
Emerging from the 'worst': An ethnography of the modern Filipino commuting culture behind the Metro Manila traffic crisis
}

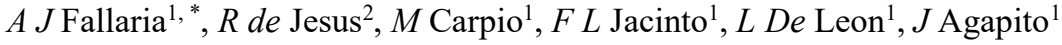 \\ , and $J G$ Ramos $^{1}$ \\ ${ }^{1}$ Student of Science, Technology, Engineering and Mathematics Strand, Senior High School \\ Department, Dr. Yanga's Colleges, Inc., Bocaue, Bulacan, Philippines \\ ${ }^{2}$ Research Coordinator, Dr. Yanga's Colleges, Inc., Bocaue, Bulacan, Philippines
}

\begin{abstract}
Metropolitan Manila has become the world's 'worst' in terms of its traffic scenarios and such crisis left an impact to the commuters which has led to the emergence of the modern Filipino commuting culture. The ethnography utilized covert participant observation in which the researchers immersed themselves in the culture and experience the activities of the commuting culture. They also conducted personal and synchronous interview to the participants involved. The findings of the study are summarized through five emergent themes which represent the roots of the culture's existence, the commuters' preferences on public transit modes, the features of Metro Manila commuting experiences, the coping mechanisms and adjustments done by commuters, and the desires and decisions for commuting experiences, respectively. Also, the mentioned culture reflected the Filipino values such as patience, crab mentality, and the misused value of resilience. The findings ended with a concrete recommendation to establish an Internet-based platform for Metro Manila commuters and a summary report intended for public transport stakeholders and public officials.
\end{abstract}

\section{Introduction}

Once dubbed the 'worst' of the globe, Metro Manila has never escaped its tremendous issue on traffic. In an evaluation made by Waze, a world-used traffic and navigation application, the metropolitan area became the world's 'worst' in terms of traffic management last 2015 (Hegina, 2015). Further transport studies in the recent decade also presented Metro Manila as one of the cities with such world traffic status [1][2]. The traffic crisis has clearly affected the city's commuters.

\footnotetext{
* Corresponding author: andrejacquestigno@gmail.com
} 
A commuter, by operational definition, is an individual who uses public transportation to go to and from a destination at a regular basis. An apparent effect of the crisis to the commuters is the longer commute time, especially during the rush hour periods. In a Boston-based study commissioned by the ride-sharing company Uber, it was revealed that individuals plying at Metro Manila spend the third longest average time being stuck in traffic every day in Asia, which is at 66 minutes [1]. Commuters also report the usual health effects of traffic such as tired muscles, mental stress, and some respiratory ailments including cough and asthma brought by the metropolitan environment as influenced by the traffic [3][4][5]. Long-term effects also follow such as low yield of Filipino employees due to becoming late in work. Moreover, a thorough 2014 report from Japan International Cooperation Agency (JICA) approximates that the worth of economic loss due to the Metro Manila traffic crisis has reached 2.4 billion pesos last 2012 [6].

Despite of the past and on-going solutions of the government about the studied issue, the crisis still remains. The current Philippine administration, however, has already initiated its road and rail projects for Metro Manila in its Build, Build, Build Program and long-term effects are expected whenever the projects are finished and set ready to take effect [6]. Yet currently, it cannot be denied that the traffic crisis still exists as it affects Filipino commuters. Aside from these effects, such dilemma has brought more complications to the Manila commuters in general.

A University of the Philippines-based study, Busina, documented interviews with individuals who regularly commute in Metro Manila. The responses- indicated that instead of making complaints on the worsening traffic situations, commuters engage to past times and other activities. It was also shown that resiliency and patience are common among Manila commuters, particularly, during the rush hour periods [7]. In a speech by Videčnik, a Graduate School of Design (GSD) professor from the Harvard University, as cited by Talabong (2018), it was implied that local commuters in Metro Manila have accepted the traffic situations as part of their culture, unconsciously disregarding the idea that they deserve to have better public transit options. The Manila traffic crisis has turned into a normal occurrence for those who are long accustomed to it.

Furthermore, the culture today of Manila commuters is likely to be influenced by their commutes such as what is revealed from some of the key findings of Bissell (2015) in an Australia-based study.It was highlighted that commuting changes the commuter himself and his relationship with the city where he commutes and his commutes are intimately connected' to the rest of his daily routine [8].

Even though there are present literature related to the study's focus, these are still not enough to embody what is named as the modern Filipino commuting culture. All in one picture, Metro Manila may be one of the 'worst' in the world in terms of traffic management, yet there are still lessons that one must learn and apply in which one can acquire from the studied culture through this ethnography.

This concern leads to the primary objective of this study and that is to identify and justify the customs of the modern Filipino commuting culture as influenced by the Metro Manila traffic crisis and its surrounding issues such as the current concerns on public transportation and infrastructures.

\section{Research methods}

The researchers utilized an ethnographic type of research design that is concerned primarily on cultures such as the study's subject - the modern Filipino commuting culture. This specific design documents cultural similarities and differences through empirical fieldwork and helps with generalizations about human behaviour and the operation or social and 
cultural systems. It, therefore, enabled researchers to link the Filipino values to the emerging customs of the said culture.

This type of study uses participant observation in which the researchers were also the participants themselves. Here, they immersed themselves in the culture and spent time with the Filipino commuting public personally experiencing the commuting activities e.g. waiting in terminals, riding trains or buses, and the like. This was done to get a sense of how they live the "commuting" life, their habits, and their interactions with each other and those around them. Upon identifying the key locations, the researchers did covert participant observation. Hereafter, short interviews and discussions were made with the people involved in the culture until 62 observations and statements from informants were recorded. The recorded data included the collation of information that reflects responses from the commuting students and workers alike, public utility vehicle (PUV) drivers, and observations of the Manila-based public transportation terminals, design of public transportation system, rail and road traffic management system. These establishes rigor of the research findings through triangulation of data sources.

There were also 11 informants who had undergone more in-depth interviews with the researchers lasting at least 30 minutes. They were scouted through purposive and convenient sampling. In addition to commuters, public utility vehicle drivers and rail transit employees were also interviewed. Five (5) of them had undergone personal interview while the 6 others had their interview through synchronous or online method. Afterwards, the statements were transcribed verbatim for data analysis.

Using the qualitative thematic analysis method by Billups (2012), the researchers were able to code each significant statement made by each informant based on its meaning [9]. After being immersed with the data and recognizing reoccurring patterns, similar meanings produced the foundation for a formulated meaning. On a contextual basis, formulated meanings that fall under the same category were the bases of the formation of theme clusters. Theme clusters that were interrelated were condensed and narrowed down which led to emergent themes.

\section{Findings}

The researchers ended with five emergent themes. The first theme, 'Factors Affecting Commuting Culture', discusses about the reasons behind the current state of the modern Filipino commuting culture. 'Public Transportation Mode Preferences' displays the considerations of commuters on choosing a mode for public transit. The third theme, 'Other Features of Metro Manila Commuting Experiences', covers the non-road-related features which can be seen in a commuting experience in Metro Manila. 'Adjustments toward Better Commuting Experiences' centers on the coping strategies of commuters before or during the commuting adversities they are facing through. The fifth and final theme, 'Remarks, Decisions and Desires for Commuting in Metro Manila', explains the changes in the commuting experiences and each commuter's desires for better commuting experiences in the future.

\subsection{Factors affecting commuting culture}

Table 1. Factors affecting commuting culture.

\begin{tabular}{|l|l|}
\hline \multicolumn{1}{|c|}{ Theme Cluster } & \multicolumn{1}{c|}{ Formulated Meanings } \\
\hline \multirow{2}{*}{$\begin{array}{l}\text { Insufficiency of public utility } \\
\text { vehicles }\end{array}$} & Insufficiency due to traffic congestions \\
\cline { 2 - 2 } & Insufficiency due to high demand \\
\cline { 2 - 2 } & Insufficiency due to government operations \\
\hline
\end{tabular}




\begin{tabular}{|l|l|}
\hline Inefficiency of rail transit & Timewasting system on passenger accommodation \\
\cline { 2 - 2 } services & Timewasting technical delays on transportation \\
\hline \multirow{4}{*}{$\begin{array}{l}\text { Ineffectiveness of policies on } \\
\text { road, traffic and transport }\end{array}$} & Defiance of traffic laws \\
\cline { 2 - 2 } & Defiance of laws on paying fares \\
\cline { 2 - 2 } & Defiance of laws on passenger accommodation \\
\cline { 2 - 2 } & Defiance of laws on surroundings \\
\cline { 2 - 2 } & Ineffectiveness of government projects, systems and operations \\
\hline
\end{tabular}

The first emergent theme collates the external factors disrupting the modern Filipino commuting culture in Metro Manila into three categories. The following clusters have to be addressed and the situations reflected a call for a recommendation for the government.

Insufficiency of public utility vehicles (PUVs) as a theme cluster, is primarily due to the following scenarios: traffic congestions, government operations and even the high demand of such. The informants shared the same sentiment on the insufficiency of PUVs to meet their transport needs particularly during rush hour periods when most commuters are present in Metro Manila. Same situations are also present in recent news articles regarding the matter (Butuyan, 2017; Kritz, 2017; Orellana, 2018) as reflected in the following statment.

"There are buses that are really overloaded to the extent that a commuter is already in contact with the closed bus door. We are overcrowded inside that even the bus conductor is cramming [at the aisle filled with passengers] just to collect fares." (Translation in Transcript no. 5)

The next cluster is about the inefficiency of rail transit services which has also become an issue for commuters in the metropolis. Rail transits, particularly the MRT-3, have constantly faced glitches and system issues which have become hindrances for better commuting experiences (Echeminada, 2017).

"For me, MRT is the worst. Even though it is fast [compared to other modes of transportation], there are a lot of issues which have badly affected the commuters especially during rush hours, for example: the train glitches, the very long queues due to an inefficient system, and many more." (Translation in Transcript no. 7)

Ineffectiveness of the policies on road, traffic and transport is also a significant element to the state of the modern Filipino commuting culture today. This also represents the lack of discipline of Filipinos in terms of following basic rules on road, traffic and transportation (Nolasco, 2016). The theme cluster also presents violations committed by commuters and drivers alike on not paying fares, rejecting passengers (dela Rosa, 2014; De Jesus, 2017; Elemia, 2017). Littering has also been prevalent in the major streets of the metropolis (Lasco, 2017). Besides these, traffic control signals, other government projects and related systems that are perceived to be ineffective to solve traffic woes are also contributors to the condition of the commuting culture today (Villas-Alvaren, 2017).

"I have constantly noticed that there is lack of discipline but I cannot generalize. Because there are jeepney drivers who unload at areas which are supposedly not for unloading, it is a cause for heavy traffic to emerge." (Translation in Transcript no. 4)

\subsection{Public Transportation Mode Preferences}

Table 2. Public Transportation Mode Preferences.

\begin{tabular}{|l|l|}
\hline \multicolumn{1}{|c|}{ Theme Cluster } & \multicolumn{1}{c|}{ Formulated Meanings } \\
\hline \multirow{2}{*}{ Commuters' preference due to time efficiency } & Factor of approachability \\
\cline { 2 - 2 } & Factor of accessibility \\
\hline \multirow{2}{*}{ Commuters' preference due to convenience } & Factors of ease and comfort \\
\cline { 2 - 2 } & Factor of security \\
\hline
\end{tabular}




\begin{tabular}{|l|l|}
\hline \multirow{4}{*}{ Commuters' preference due to affordability } & Factor of cost-effectiveness \\
\cline { 2 - 2 } & $\begin{array}{l}\text { Preference of time efficiency and convenience } \\
\text { over affordability }\end{array}$ \\
\hline \multirow{4}{*}{ Commuters' preference due to availability } & \begin{tabular}{l} 
Limited modes of transportation \\
\cline { 2 - 2 }
\end{tabular} \\
$\begin{array}{l}\text { First preference persistence despite unfavorable } \\
\text { circumstances }\end{array}$ \\
\cline { 2 - 2 } & $\begin{array}{l}\text { Alternative preference due to insufficiencies on } \\
\text { first preference }\end{array}$ \\
\hline
\end{tabular}

The second emergent theme goes on with the criteria of commuters on their desired modes of public transit. These preferences have become the basis of the researchers for commuters' rights.

The first two clusters, time efficiency and convenience, are more prioritized than the other factors for their preferences. Time efficiency is what commuters look after, particularly in transport network corporations (TNCs) such as Grab and Uber, which are more efficient than taxi operators (Los Baños, 2017). The Helsinki Regional Transport Authority (2010) noted that transportation can be defined as efficient for the accessibility of stations, terminals or stops where one commuter can reach by walking in a reasonable amount of time. For convenience, Sundström and Radon (2015) clearly defined this as a vital consideration for commuters in preferring transport modes [10]. Safety is also considered by some commuters because of the hostile setting of Metro Manila for crime involving PUVs (Overseas Security Advisory Council, 2017).

Meanwhile, the least prioritized factor, based from the findings, is the transportation affordability. Public transport is considerably inexpensive for an average Filipino commuter; however prices are slightly raised in more convenient PUVs like in airconditioned ones (Adrian, 2017). Although some rely on which mode is of lower cost, other commuters take affordability as of less concern.

The last resort for commuters, especially whenever they are caught between rush hour periods in Metro Manila, is the factor of availability, in which the commuter does not depend anymore on time efficiency or convenience. In this case, the commuter takes risks by facing adversities during his commuting experiences. This is commonly seen in situations inside buses or even trains at MRT-3 as this reflects how Filipinos endure the struggles of commuting while striving to be patient (Francisco, 2016b). In a documentary episode directed by Dela Cruz (2017) for Reporter's Notebook, commuters along EDSA struggled to reach in buses until they 'were packed like sardines in a can.'

\subsection{Other Features of Metro Manila Commuting Experiences}

Table 3. Other Features of Metro Manila Commuting Experiences.

\begin{tabular}{|c|c|}
\hline Theme Cluster & Formulated Meanings \\
\hline \multirow{3}{*}{$\begin{array}{l}\text { Commuting environment of Metro } \\
\text { Manila and its surrounding systems }\end{array}$} & Presence of queue systems in riding \\
\hline & Options for more efficient services \\
\hline & Unfavorable environmental and ergonomic features \\
\hline \multirow{2}{*}{ Time lost due to commuting } & Time consumed due to waiting \\
\hline & Time consumed due to traffic congestions \\
\hline \multirow{4}{*}{$\begin{array}{l}\text { Consequences of commuting } \\
\text { adversities }\end{array}$} & Stress and exhaustion from commuting experiences \\
\hline & Futile pre-commuting adjustments \\
\hline & Inevitable late arrival \\
\hline & Weariness brought by routine commuting experiences \\
\hline
\end{tabular}


The third emergent theme reflects the other features of the commuting experiences in Metro Manila. Aside from the road and traffic scenes in Metro Manila, commuters have shared some facets that improve or worsen their commuting experiences. Some commendable facets have to be maintained; however, there are also factors which need improvement.

Other public transit terminals are observed to have queue systems which make a more organized system in taking rides for commuters, while some have no distinct lanes. For more efficient services, Grab and Uber set an example as commuters have trusted these services more than taxis' (Tulio, 2017). For rail transits, Beep ${ }^{\mathrm{TM}}$ cards are introduced to commuters to ease the congestion of commuters lining up to purchase tickets as it will reduce the time needed to insert or collect the cards through slots (Jimenez-David, 2015). Meanwhile, the unfavorable features have become disturbing adversities of which commuters have to face in their commuting experience. The heat inside non-air-conditioned PUVs, overcrowding, untidiness and narrow sidewalks are some instances.

The second cluster is about the time that is consumed in every commuting experience. Several articles feature commuters' anecdotes on their experiences in commuting, from the time they have spent from waiting for a ride and the time lost as well in taking it along the horrendous traffic scenario of Metro Manila's roads (CNN Philippines, 2015; Cheang, 2016; Mamuyac, 2016). The cluster is an embodiment of the patience of Filipinos, or their willingness to endure their time-consuming commutes.

"...it takes 3 hours to 3 and a half; that is how I see it. It really demands one to be extremely patient." (Translation in Transcript no. 4)

The last illustrates the consequences of the commuting adversities faced by commuters. Hoehner et al. (2012) revealed in their study that traffic congestions are correlated to higher risks of chronic stress. Still according to Hoehner (2012), due to the stress experienced in travel, commuters may develop heart-related diseases [5]. In some cases, commuters' adjustments of leaving even earlier for school or work still do not count because of traffic jams (Teitell, 2017). Also, one apparent result of traffic jams is tardiness of employees in their workplaces, the same for students to their schools. In the long run, some commuters view their usual commuting experiences as tiresome as their view on commuting has changed due to the repeated exposure to doing so [11].

\subsection{Adjustments toward Better Commuting Experiences}

Table 4. Adjustments toward Better Commuting Experiences.

\begin{tabular}{|l|l|}
\hline \multicolumn{1}{|c|}{ Theme Cluster } & \multicolumn{1}{c|}{ Formulated Meanings } \\
\hline Coping by self-distraction & Distraction by self-entertainment \\
\cline { 2 - 2 } & Distraction by communication \\
\hline \multirow{2}{*}{$\begin{array}{l}\text { Rest opportunity during } \\
\text { commuting }\end{array}$} & Distraction by self-productivity \\
\hline \multirow{2}{*}{$\begin{array}{l}\text { Self-reliance against } \\
\text { unfavorable situations }\end{array}$} & Rest opportunity due to physiological factors \\
\cline { 2 - 2 } & Rest opportunity due to inactivity or comfort \\
\hline \multirow{2}{*}{$\begin{array}{l}\text { Adjustments toward efficient } \\
\text { commuting }\end{array}$} & Unhealthy risking for efficient commuting \\
\cline { 2 - 2 } & Adjustment brought by being accustomed to the crisis \\
\cline { 2 - 2 } & Adjustment against a hostile and unhealthy environment \\
\cline { 2 - 2 } & Pre-commuting adjustments \\
\cline { 2 - 2 } & Switching to alternative PUV routes \\
\cline { 2 - 2 } & Shelter adjustment \\
\cline { 2 - 2 } & Recalling purpose on commuting \\
\hline
\end{tabular}

The fourth emergent theme embodies the coping strategies of Metro Manila commuters before and during their commuting experiences. Derived from the theme is the desire of Filipino commuters to gain a time-efficient trip that they deserve. 
Most of the time, commuters find ways to distract themselves from the traffic scenario and from their uncomfortable commutes. Several activities that they do during commutes are watching TV series' episodes or movies, listening to music, socializing with peers or relatives, or even becoming productive by doing office works or assignments during travel [8]. All of these activities reflect the sense of joy and pakikitungo (civility), a form of pakikipagkapwa (relational interaction) of Filipinos, as well as diligence or kasipagan (Wong, 2012; Pacana, 2017). One example is shown in a statement of an informant below:

"Sometimes, while already onboard... on train or on a bus, we are still using our cellular phones to distract ourselves from discomfort brought about by congestions and lengthy trips." (Translation in Transcript no. 8)

Other commuters treat their commutes as a rest opportunity, especially when their commutes are taking longer than they should be. Commuters take rest either due to the stress or fatigue from their work or studies, or just due to boredom or inactivity (Mann, 2017).

Every commuter of Metro Manila has to train himself in the uphill battle of commuting and self-reliance is his key. Some commuters, due to unavailability, take risks even if it involves violating the law (e.g. riding overloaded buses) (Corpuz, 2014). Other commuters are forced to walk instead due to the lack of available public transit modes at some points (Nebrija, 2016). Meanwhile, others are observed to adjust by wearing caps or face masks to adjust to the unsafe environment that Metro Manila has. For Mijares et al. (2016), this symbolizes the Filipino resilience which is a value that is commonly exhibited by Filipinos during tragedies, for they became accustomed to a particularly thwarting situation [11]. Commuters cope by accepting the situation, unconsciously disregarding that they can have better commuting experiences.

At most times, Metro Manila commuters follow some adjustments before they star commuting. They adjust by waking up and departing from their homes earlier to get to their desired destinations as early as possible (Natividad, 2017; Tadeja, 2017). Other commuters rely on alternative routes which provide them faster commutes while there are some who adjusts by moving to a new home near to their workplaces (iMoney, 2014; Unpakt, 2017). The fourth cluster represents the values of flexibility and the sense of purpose of Filipinos as they still go on with their commutes [12]. A statement below mirrors the final cluster of this emergent theme:

\subsection{Remarks, Decisions and Desires for Commuting in Metro Manila}

Table 5. Remarks, Decisions and Desires for Commuting in Metro Manila.

\begin{tabular}{|c|c|}
\hline Theme Cluster & Formulated Meanings \\
\hline \multirow{2}{*}{$\begin{array}{lcc}\text { Changes } \quad \text { toward } & \text { current } \\
\text { commuting experiences } & \end{array}$} & Stagnancy and worsening of commuting experiences \\
\hline & Improvements on commuting experiences \\
\hline \multirow{2}{*}{$\begin{array}{l}\text { Decisions on switching to } \\
\text { private transportation }\end{array}$} & Switching to private vehicles \\
\hline & Rejection due to situation perception \\
\hline \multirow{2}{*}{$\begin{array}{l}\text { Cultural acceptance of the traffic } \\
\text { crisis }\end{array}$} & Refusal of idea due to situation perception \\
\hline & Developing acceptance of the crisis \\
\hline \multirow{4}{*}{$\begin{array}{l}\text { Insights toward better } \\
\text { commuting experiences }\end{array}$} & Desires for time-efficient commuting experiences \\
\hline & Desires for law amendments and implementation \\
\hline & Desires for improved public transportation system \\
\hline & Desires for proper commuting etiquette \\
\hline
\end{tabular}

The ultimate emergent theme discusses the changes in commuting experiences and the decisions and desires of the commuters for better commuting experiences in the future. The 
desires are used as a basis for the researchers on their recommendation to form a Code for Commuters' Rights.

For Metro Manila commuters, majority view that nothing changed or their experiences have worsened while some noted improvements (ABS-CBN News, 2016).

Commuters of Metro Manila are divided on their decisions in purchasing private vehicles. Others intend to acquire a car or even motorcycle to end their woes in commuting whereas there are some who rethink first if it will just add to the current traffic density (Lucas, 2014; Remo, 2016).

Metro Manila commuters are also divided when it comes to accepting the traffic crisis as part of the Filipino culture. Some commuters believe that there will always be solutions to the crisis and accepting it is not an answer while others have developed acceptance of the crisis as they have accepted the way their daily journeys are (Friedrich Naumann Foundation for Freedom, 2017). This reflects the optimism of Filipinos for future possibilities and at the same time the pessimism toward the current situation [13].

"But for a long time we have been experiencing this kind of issue in Metro Manila,

commuters are already accustomed to this system, which is not good." (Translation in Transcript no. 7)

Lastly, Filipinos have their desires for future commuting experiences, from getting time-efficient transport services, a law-abiding culture on the roads, improved public transit systems and discipline of fellow commuters.

"With the help of the right discipline, knowledge and our submission to the traffic rules,

I believe that these can contribute solving the traffic problem." (Translation in Transcript no. 10)

\section{Conclusions}

From understanding the findings of the ethnography along with its support from existing literature, the study has come up with the following conclusions:

- Insufficiency of PUVs, inefficient public transit system and ineffectiveness of the policies on road, traffic management and transport are all precursors of the current state of the modern Filipino commuting culture. Here, Manila commuters identify their mode preference of public transit using the factors of time efficiency and convenience. Affordability is of less concern while availability is used in times of rush hours where commuters do not rely anymore on the time efficiency and convenience.

- The surrounding systems which are essential in building a commuting environment that is conducive for commuting experiences are the presence of queues and efficient payment systems. Still, there are factors that inhibit commuters from attaining better commuting experiences such as unfavorable environment and poor ergonomic conditions.

- Commuters share the same sentiment of tardiness and stress endured in their commutes. During commutes, they cope by doing activities that would distract them while other commuters use this time as an opportunity to rest. Commuters usually minimize the health risks made by the unfavorable situations while others endure these conditions.

- Likewise, the state of cultural acceptance of the traffic crisis in Metro Manila depends as well on the perspective of a commuter: acceptance or refusal. Acceptance is primarily influenced by the resilience by being accustomed to the crisis while refusal is the optimism in which commuters still keeping the faith for possible solutions.

- The commuters then have their desires for better commuting experiences in the future such as being time-efficient, transport and traffic law amendments and stricter implementation of these laws, a more organized public transportation system and a proper commuting etiquette for all commuters. 
- The modern Filipino commuting culture is an illustration of the Filipino values. The affirmative values present are the values of adaptability, optimism, maintaining satisfying interpersonal relationships, emphasis on personal convenience, diligence, the sense of joy, and the sense of meaning and purpose. The negative values recognized in the said culture are lack of discipline and crab mentality. A misused value is the value of resilience where commuters got accustomed to their unsatisfying and uncomfortable commuting experiences like these are just parts of their everyday life.

On the basis of all this, the researchers devised The Filipino Commute, a website and a social media platform that features news on transportation and traffic situations in the Philippines and other articles that are intended for the benefit of Metro Manila commuters. Complaints on PUV drivers and franchises can also be made through this platform. Also, a report entitled "The Filipino shaped by his commuting experiences: A research-based summary report to stakeholders and public officials" was sent to public transportation stakeholders and government officials, which may serve as basis for the transit-oriented development of Metro Manila.

In addition, the findings have led the researchers to the design of the Code for Filipino Commuters' Rights that is composed of ten rights in which each public transport service provider should adhere to such as right to availability, right to accessibility, right to timeefficient services, right to safety, right to affordability, right to convenience, right to environment-friendly services, right to making reviews, suggestions and complaints, right to accountability, and right to welcoming services.

\section{References}

1. Billups F D 2012 Qualitative Data Analysis: An Overview for Beginning Qualitative Researchers The NERA Researcher $\mathbf{5 0}$ pp 8-10

2. Bissell D 2015 Understanding the impacts of commuting: Research report for stakeholders (Canberra, Australia: Australian National University)

3. Chin V, Jaafar M, Moy J, Phong M, Wang S, McDonell M \&Prawiradinata I 2017 Unlocking Cities: The impact of ridesharing in Southeast Asia and beyond (Massachusetts, United States: Boston Consulting Group)

4. Hoehner C, Barlow C, Allen P \& Schootman M 2012 Commuting Distance, Cardiorespiratory Fitness, and Metabolic Risk American Journal of Preventive Medicine $\mathbf{4 2}$ pp 571-578

5. Japan International Cooperation Agency 2014 Roadmap for Transport Infrastructure Development for Metro Manila and Its Surrounding Areas (Region III and Region IV-A)

6. Levy J, Buonocore J \& Stackelberg K 2010 Evaluation of the public health impacts of traffic congestion: a health risk assessment Environmental Health 965

7. Luz S G, Morano S K \& Santos A 2015 "Sociological Picture and Analysis on Filipino Transport Systems" Busina: Current State, Innovation and Emerging Filipino Values on Metro Manila (Quezon City, Philippines: University of the Philippines - Diliman)

8. Menguito M L \& Teng-Calleja M 2010 Bahala Na as an Expression of the Filipino's Courage, Hope, Optimism, Self-efficacy and Search for the Sacred Philippine Journal of Psychology 43 pp 1-26

9. Mijares A C, Suzuki M \& Yai T 2016 Passenger Satisfaction and Mental Adaptation under Adverse Conditions: Case Study in Manila Journal of Public Transportation 19 pp 144-160

10. Numbeo 2015 Traffic Index for Country 2015 Mid-Year (Serbia: Numbeo doo, Inc.) 
11. Sundström M \& Radon A 2015 Utilizing the Concept of Convenience as a Business Opportunity in Emerging Markets Organizations and Markets in Emerging Economies 6 pp 7-21

12. Yabut H 2017 The Development of the Filipino Spirituality Scale $10^{\text {th }}$ DLSU Arts Congress: The Filipino and the Sacred 9 (Manila, Philippines: De La Salle University)

13. Zhang K \& Batterman S 2013 Air pollution and health risks due to vehicle traffic Science of The Total Environment 450-451 pp. 307-316 